\title{
A Parametric Study on Flange Vertical Buckling of Hybrid Steel Girders
}

\author{
T. Ueda, Y. Matoge \& S. Shimizu \\ Shinshu University, Nagano, Japan \\ G.Fujita \& N.Tanaka \\ Miyaji Engineering CO., LTD, Ichihara, Japan
}

\begin{abstract}
It is known that flange vertical buckling arises in a steel girder having very weak web plate, and it is generally believed that vertical buckling does not occur in a steel girder with "normal" section dimensions. However, in the author's experimental test, unexpected vertical buckling was observed. In this paper, a series of numerical analysis is made on flange vertical buckling of hybrid steel girders, and the limit web width-thickness ratio and so on are studied. The results indicate that the web width-thickness ratio has small contribution to the vertical buckling behaviour.
\end{abstract}

\section{INTRODUCTION}

Flange vertical buckling is one of the collapse patterns of an I-shaped steel plate girder. When flange vertical buckling occurs, a part of the flange plate deforms almost vertically into the web plate. Basler et al. presented a formula to estimate the limit of the width-thickness ratio of the web plate which prevent of flange vertical buckling (Basler \& Thürlimann 1961, Dowling 1992). Generally, it is considered that flange vertical buckling occurs with very slender or weak web plate, and in the steel plate girder having "normal" section dimensions, vertical buckling does not occur.

On the other hand, a hybrid steel girder is an Ishaped plate girder having flange plates made of high-strength steel and the web plate with normal steel. Therefore, in the ultimate state of a hybrid steel girder, the top and the bottom parts of the web plate shall be yielded although the flange plates are still in the elastic range.

Two authors of this paper have carried a series of experimental test on behaviour of hybrid steel girders (Shimizu et al. 2003a,b). According to the Basler's formula, the test models have the section dimensions with which vertical buckling does not occur. However, in one of the test models, unexpected flange vertical buckling was observed. In the Figure 1, flange vertical buckling observed during the test is shown. In this photo, it is found that the flange plate deforms downwards almost vertically.
The experimental test is carried out on the test girders subjected to two symmetric point loadings as illustrated in Figure 2. After the test, the authors reviewed the test records carefully, and it is found that the magnitude of the two loadings is different by about $1 \%$ to each other. The authors also made the numerical analysis on the test model, and it is clarified that the asymmetricity of the loadings prompts vertical buckling, and the vertical buckling strength may be affected by the web and flange thickness themselves rather than the width-thickness ratio of the web plate (Shimizu et al. 2011, Matoge et al. 2012).

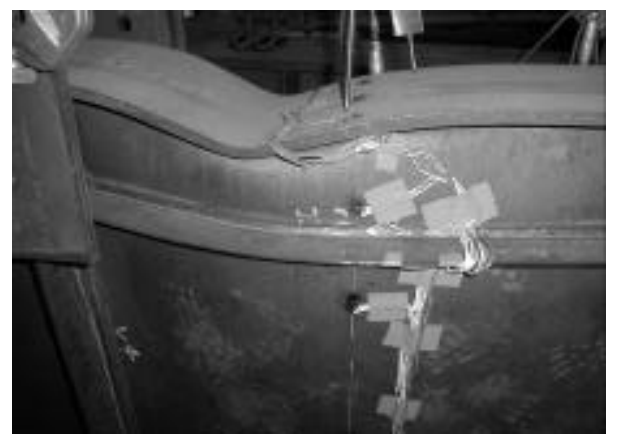

Figure 1. Observed flange vertical buckling

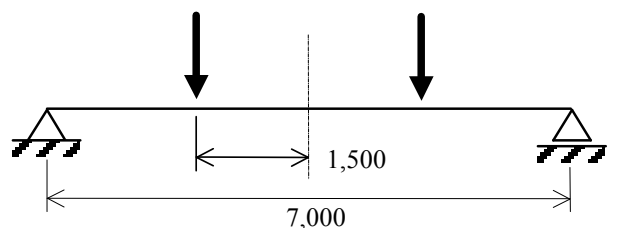

Figure 2. Loadings of experimental test 
In the current paper, the numerical study is made on flange vertical buckling of hybrid steel girders with observing the thickness of the web plate.

\section{NUMERICAL MODELS AND NUMERICAL METHOD}

\section{$2.1 \quad$ Numerical Models}

In the Figure 3, a typical numerical model used for the analysis is illustrated. This numerical model has its shapes and dimension generally same to the test model, excepting the web depth and the flange thickness. The test model has the nominal flange thickness of $15 \mathrm{~mm}$ and the nominal web depth of $900 \mathrm{~mm}$. However, in the current study, flange thickness and the web depth are varied $10-20 \mathrm{~mm}$ and $600-1200 \mathrm{~mm}$ respectively. The web thickness and the flange width are fixed to $4.5 \mathrm{~mm}$ and 200 $\mathrm{mm}$ respectively. The span length of the model is $7000 \mathrm{~mm}$, and the transverse stiffeners and the longitudinal stiffeners are installed as illustrated in the figure.
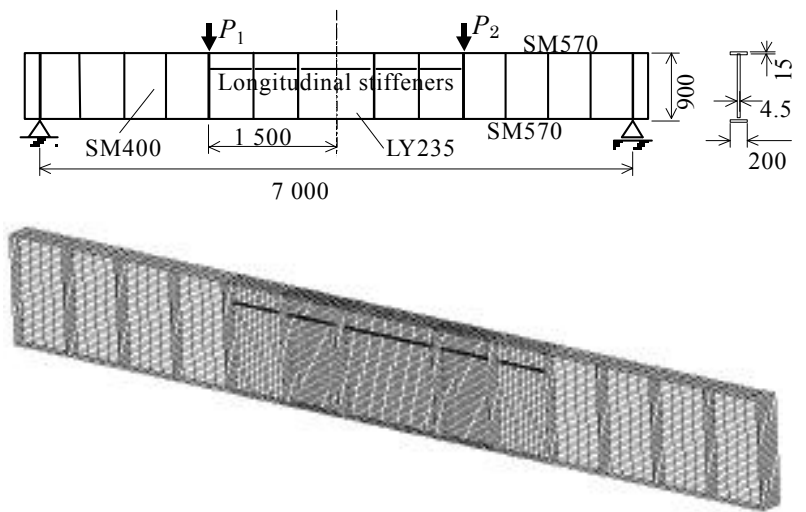

Figure 3. Example of the model layout and FEM mesh pattern

The numerical model is subjected to 2 loadings $P_{1}$ and $P_{2}$, however the load $P_{1}$ is kept greater by $1 \%$ than $P_{2}$, because asymmetricity of the loadings is considered to be a cause of the vertical buckling as mentioned in the Section 1 of this paper.

The model is supported laterally to avoid the lateral buckling as same to the test model.

\subsection{Numerical Method}

The numerical analysis is made as an the elastoplastic large deflection problem. The materials assumed in the analysis are the grade SM500 highstrength steel for the flange plates, SM400 normal steel for the web plate except the center part, and for the center of the web LY235 low yield steel is considered, as same to the test model. In the Table 1 , the material properties, Young's Modulus $E$, yield stress $\sigma_{\mathrm{y}}$ and Poisson's ratio $v$, used in the analysis are summarized. These values are those measured through the tensile coupon test made on the experimental model.

Table 1. Material properties.

\begin{tabular}{llll}
\hline Grade & $E$ & $\sigma_{\mathrm{y}}$ & $v$ \\
\cline { 2 - 4 } & $\mathrm{GPa}$ & $\mathrm{MPa}$ & \\
\hline SM570 & 199 & 596 & 0.29 \\
SM400 & 188 & 433 & 0.28 \\
LY235 & 199 & 265 & 0.29 \\
\hline
\end{tabular}

The analysis is made with using the computer program package MSC Mark.

\subsection{Ultimate width-thickness ratio}

According to Basler et al. (1961), the ultimate width-thickness ratio to prevent of flange vertical buckling is defined with the formula

$\frac{b}{t} \leq \sqrt{\frac{\pi^{2} E}{24\left(1-v^{2}\right)} \frac{A_{w}}{A_{f}} \frac{1}{\sigma_{f} \varepsilon_{f}}}$

where $b$ denotes the web depth (width), $t$ the web thickness, $E$ the Young's modulus of the web plate, $A_{w}$ the area of the web plate, $A_{f}$ the area of the flange plate, $\sigma_{f}$ the yield stress of the flange plate and $\varepsilon_{f}$ denotes the yield strain of the flange plate. Substituting the measured material properties into (1), the limit of the width-thickness ratio is obtained to $b / t=254$. On the other hand, the test model has a web width-thickness ratio of 200 and less than 254 . This means that vertical buckling does not occur in this model.

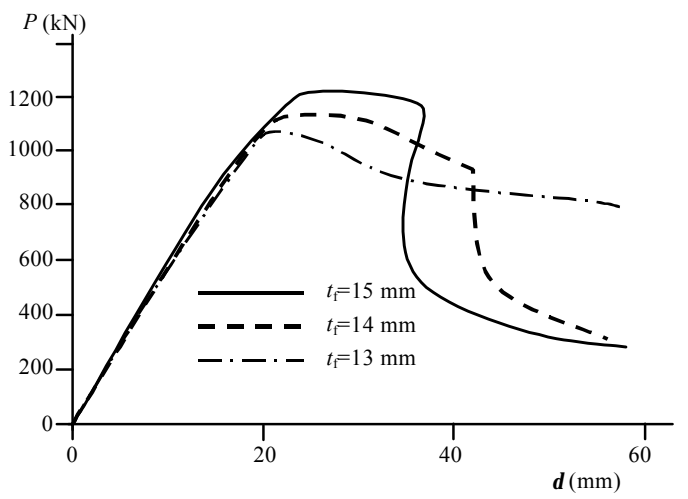

Figure 4. Load-deflection relations for $b=1200 \mathrm{~mm}$ models

\section{NUMERICAL RESULTS}

\subsection{Load-deflection relation and buckling pattern}

In Figure 4, the load-deflection relations $(P-\delta$ curves) of the numerical models with web depth $b=1200 \mathrm{~mm}$ and the flange thickness $t_{\mathrm{f}}=15 \mathrm{~mm}, 14$ $\mathrm{mm}$ and $13 \mathrm{~mm}$ are plotted. The vertical axis of this figures is the load $P_{1}$ in the figure 3 , and the 
horizontal axis denotes the vertical displacement of the top flange at the center of the model girders.

Figures 5, 6 and 7 show the deformation patterns of these models at the final stage, i.e. the endmost of plotted curves in Figure 4.

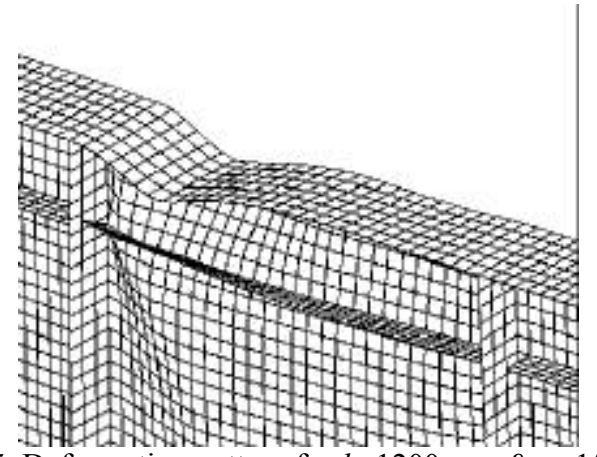

Figure 5. Deformation pattern for $b=1200 \mathrm{~mm} \& t_{\mathrm{f}}=15 \mathrm{~mm}$

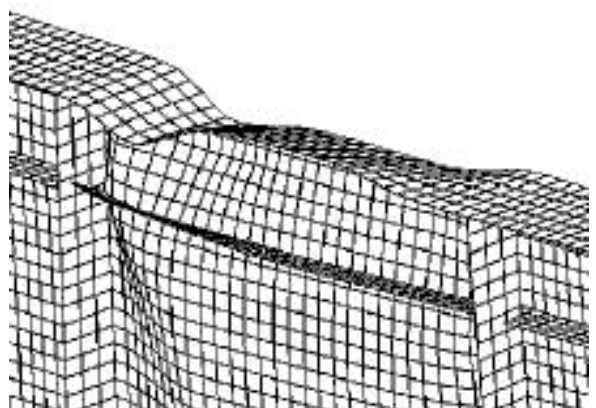

Figure 6. Deformation pattern for $b=1200 \mathrm{~mm} \& t_{\mathrm{f}}=14 \mathrm{~mm}$

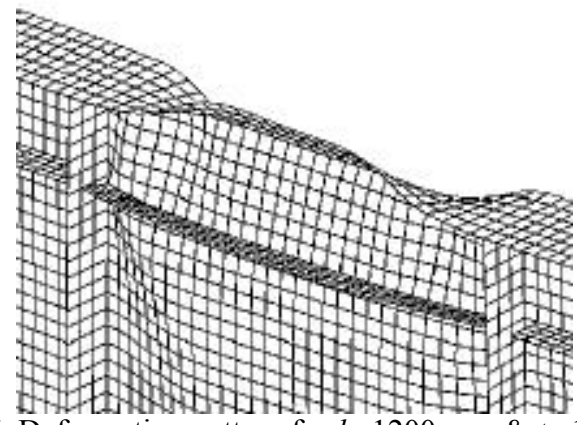

Figure 7. Deformation pattern for $b=1200 \mathrm{~mm} \& t_{\mathrm{f}}=13 \mathrm{~mm}$

The $P-\delta$ curve of the model of flange thickness $t_{\mathrm{f}}=15 \mathrm{~mm}$ in the Figure 4 indicates that the load of this model increases almost linearly up to the peak load of $P_{\max }=1213 \mathrm{kN}$. After the peak, the curve stayed horizontally to the displacement $\delta$ is reached to approx. $40 \mathrm{~mm}$, and then decreases very suddenly to the load of about $500 \mathrm{kN}$. In this model, as shown in the Figure 5, the flange plate deforms vertically into the web plate at the final stage. This deformation pattern is very similar to the deformation shown in the photo of the figure 1, thus it is found that flange vertical buckling occurs in this model. Observing the development of deformation of this model, this deformation pattern initiated when the load begins to decrease rapidly. That is, the vertical buckling occurs with the rapid decrease of the load.
On the other hand, the model with $t_{\mathrm{f}}=13 \mathrm{~mm}$ has the $P-\delta$ relation which decreases very gradually after the peak load of $P_{\max }=1067 \mathrm{kN}$. Unlike to the model of $t_{\mathrm{f}}=15 \mathrm{~mm}$, in this model, the flange plate has the torsional deformation as shown in Figure 7. Thus, in this model, flange torsional buckling occurs instead of vertical buckling.

The model with $t_{\mathrm{f}}=14 \mathrm{~mm}$ behaves with the characteristics of both the models with $t_{\mathrm{f}}=13 \mathrm{~mm}$ and $t_{\mathrm{f}}=15 \mathrm{~mm}$. As shown in the $P-\delta$ relation in Figure 4, after the peak load of $P_{\max }=1138 \mathrm{kN}$, first, the load decreases gradually as similar to the model with $t_{\mathrm{f}}=13 \mathrm{~mm}$. At this stage, the flange plate shows the torsional deformation pattern. However, when the deflection $\delta$ exceeds approx $40 \mathrm{~mm}$, suddenly the load begins to decrease rapidly, and the flange plate begins to deform vertically. Finally, this model has the deformation pattern of the flange vertical buckling together with the flange torsional buckling as shown in Figure 6.

The above descriptions are true for the case that the web depth of $b=1200 \mathrm{~mm}$. However, in all other cases, similar results are obtained. That is, with the thicker flange plate, flange vertical buckling occurs, and flange torsional buckling arises with thinner flange. The combined buckling pattern of the vertical buckling and torsional buckling was observed with the "border" flange thickness of the vertical and torsional buckling.

\subsection{Buckling pattern and maximun load}

In the Table 2, the peak loads and buckling pattern types of the numerical models according to the web depth $b$ and the flange thickness $t_{\mathrm{f}}$ are summarized.

Table 2 Summary of $P$ max with buckling patterns

\begin{tabular}{cccccc}
\hline$t_{\mathrm{f}}$ & $b=600 \mathrm{~mm}$ & $b=750 \mathrm{~mm}$ & $b=900 \mathrm{~mm} b$ & $b$ & \multicolumn{3}{c}{} \\
\hline $\mathrm{mm}$ & $\mathrm{kN}$ & $\mathrm{kN}$ & $\mathrm{kN}$ & $\mathrm{kN}$ & $\mathrm{kN}$ \\
\hline 10 & $414 \mathrm{~T}$ & $533 \mathrm{~T}$ & $653 \mathrm{~T}$ & $764 \mathrm{~T}$ & $848 \mathrm{~T}$ \\
\hline 11 & $453 \mathrm{~T}$ & $580 \mathrm{~T}$ & $708 \mathrm{~T}$ & $828 \mathrm{~T}$ & $924 \mathrm{~T}$ \\
\hline 12 & $490 \mathrm{~T}$ & $627 \mathrm{~T}$ & $762 \mathrm{~T}$ & $893 \mathrm{~T}$ & $990 \mathrm{~T}$ \\
\hline 13 & $528 \mathrm{~T}$ & $672 \mathrm{~T}$ & $816 \mathrm{C}$ & $957 \mathrm{C}$ & $1067 \mathrm{~T}$ \\
\hline 14 & $564 \mathrm{~T}$ & $718 \mathrm{~T}$ & $870 \mathrm{C}$ & $1021 \mathrm{C}$ & $1138 \mathrm{C}$ \\
\hline 15 & $601 \mathrm{C}$ & $763 \mathrm{C}$ & $924 \mathrm{~V}$ & $1083 \mathrm{~V}$ & $1213 \mathrm{~V}$ \\
\hline 16 & $637 \mathrm{~V}$ & $810 \mathrm{~V}$ & $978 \mathrm{~V}$ & $1146 \mathrm{~V}$ & $1290 \mathrm{~V}$ \\
\hline 17 & $674 \mathrm{~V}$ & $854 \mathrm{~V}$ & $1032 \mathrm{~V}$ & $1209 \mathrm{~V}$ & $1365 \mathrm{~V}$ \\
\hline 18 & $710 \mathrm{~V}$ & $899 \mathrm{~V}$ & $1086 \mathrm{~V}$ & $1270 \mathrm{~V}$ & $1439 \mathrm{~V}$ \\
\hline 19 & $746 \mathrm{~V}$ & $945 \mathrm{~V}$ & $1140 \mathrm{~V}$ & $1332 \mathrm{~V}$ & $1512 \mathrm{~V}$ \\
\hline 20 & $782 \mathrm{~V}$ & $990 \mathrm{~V}$ & $1194 \mathrm{~V}$ & $1396 \mathrm{~V}$ & $1585 \mathrm{~V}$ \\
\hline
\end{tabular}

$\mathrm{V}$ : flange vertical buckling

C: combination of flange vertical and torsional buckling $\mathrm{T}$ : flange torsional buckling

In this table, the character " $V$ " following the peak load denotes the model has flange vertical buckling pattern, "C" the combination of flange vertical and torsional buckling, and " $T$ " shows flange torsional buckling occurred. The peak loads of the numerical 
models are also plotted in Figure 8 according to the flange thickness.

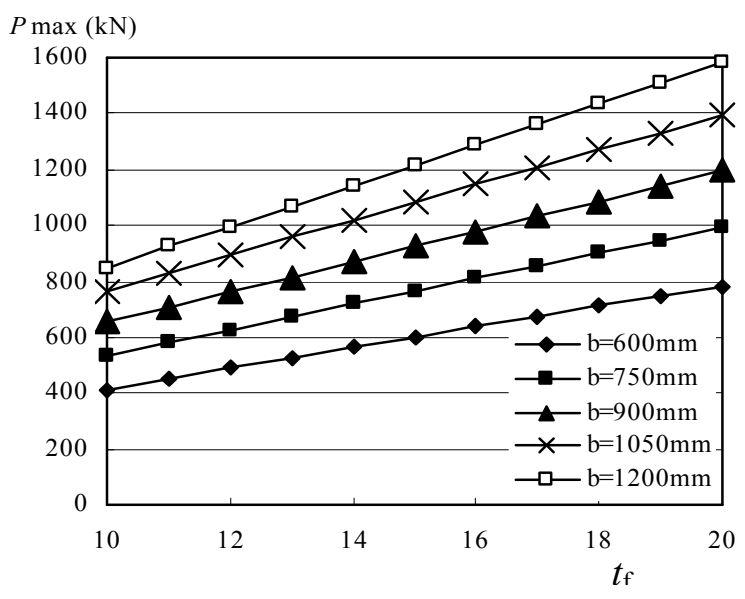

Figure 8 Peak load according to flange thickness

The table 2 and the figure 8 indicate that the peak load increases almost linearly according to flange thickness, and larger flange thickness brings the larger buckling strength. However, as shown in the table 2, the buckling pattern is varied with the flange thickness. For all web depth, models with smaller flange thickness suffer flange torsional buckling, and thicker flange brings flange vertical buckling. The "border" thickness of flange vertical buckling and torsional buckling is approximately $14-15 \mathrm{~mm}$, regardless of the web depth.

Table 3 Critical width-thickness ratios

\begin{tabular}{|c|c|c|c|c|c|}
\hline $\begin{array}{c}t \mathrm{f} \\
\mathrm{mm}\end{array}$ & $\begin{array}{l}b=600 \mathrm{~mm} \\
(b / t=133)\end{array}$ & $\begin{array}{l}b=750 \mathrm{~mm} \\
(b / t=167)\end{array}$ & $\begin{array}{l}b=900 \mathrm{~mm} \\
(b / t=200)\end{array}$ & $\begin{array}{c}b=1050 \mathrm{~mm} \\
(b / t=233)\end{array}$ & $\begin{array}{c}b=1200 \mathrm{~mm} \\
(b / t=267)\end{array}$ \\
\hline 10 & 260 & 291 & 318 & 344 & 368 \\
\hline 11 & 248 & 277 & 304 & 328 & 351 \\
\hline 12 & 237 & 265 & 291 & 314 & 336 \\
\hline 13 & 228 & 255 & 279 & 302 & 322 \\
\hline 14 & 220 & 246 & 269 & 291 & 311 \\
\hline 15 & 212 & 237 & 260 & 281 & 300 \\
\hline 16 & 206 & 230 & 252 & 272 & 291 \\
\hline 17 & 199 & 223 & 244 & 264 & 282 \\
\hline 18 & 194 & 217 & 237 & 256 & 274 \\
\hline 19 & 189 & 211 & 231 & 249 & 267 \\
\hline 20 & 184 & 206 & 225 & 243 & 260 \\
\hline
\end{tabular}

Table 3 shows the critical width-thickness ratios $b / t$ estimated with the Baslers' formula (1). In the top row of this table, the own $b / t$ value for each flange depth is also indicated. This table means that vertical buckling shall occur when the estimated critical $b / t$ value is smaller than $b / t$ of each flange depth. With this table, it is suggested that vertical buckling arises only in the model with $b=12 \mathrm{~mm}$ and $t_{\mathrm{f}}=20 \mathrm{~mm}$, which has the critical $b / t$ of 260 . However, results described in this paper indicate vertical buckling occurs in the models with the flange thickness larger than about $15 \mathrm{~mm}$.

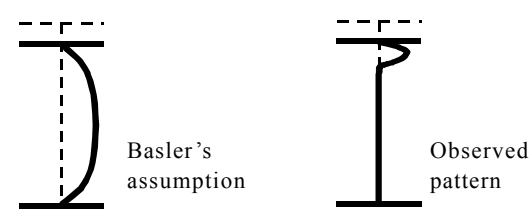

Figure 9 Observed and assumed deformation patterns

The Baslers' formula (1) is derived through the buckling strength of web plate with assumption that the web plate deforms as the pattern shown in the left of Figure 9. However, the authors' test and the numerical results indicate that the web plate deforms as right pattern in the figure. This suggests that the formula (1) is not appropriate to estimate the vertical buckling behaviour, and the new formula or the new criteria is required in which flange strength is taken into account.

\section{CONCLUSION}

In this paper, numerical analyses are made on the flange vertical buckling of hybrid steel girders, and very similar deformation pattern is obtained to the authors' experimental test. The numerical results also suggest that the web width-thickness ratio has very small contribution to the vertical buckling behaviour. Therefore the authors feel that a new formula is required to deal with vertical buckling.

\section{REFERENCES}

Basler,K \& Thürlimann B. 1961. Strength of Plate Girders in Bending, Proc ASCE, Vol.87, ST6, 153-181

Dowling,P.J. (ed). 1992. Constructional Steel Design, An International Guide, Elsevier.

Matoge,Y., Shimizu,S., Yamasaki,Y., Fujita,G. \& Tanaka,N., 2012. Vertical Buckling Behaviour Of Hybrid Steel Girders, Proc.of Stability of Structures XIII-th Symposium, 467-476, Zakopane, Poland.

Shimizu, S., Zhang, J., Tanaka, N., Akehashi, K. \& Nakai, H. 2003. An Experimental Study on Ultimate Strength Behaviour of Hybrid Steel Plate Girders, Steel Construction Engineering, JSSC (Japanese Society of Steel Construction), 10: 51-60. (in Japanese)

Shimizu, S. Zhang, J. Nakada, N. Tanaka, N. \& Nakai, H. 2003. Effect of Stiffeners in Hybrid Steel Plate Girders, Steel Construction Engineering, JSSC (Japanese Society of Steel Construction), 10: 43-50. (in Japanese)

Shimizu,S., Yamasaki,Y. \& Tanaka,N. 2011. The Numerical Analysis on Flange Vertical Buckling in Hybrid Steel Girders, AIP Conf. Proc. 1389, ICNAAM 2011. 1668-1671, Halkidiki, Greece. 